\title{
Principles of sustainable development for rural tourism synergy
}

\author{
Alexey Anokhin, and Elena Kropinova* \\ The Immanuel Kant Baltic Federal University, 236041 Kaliningrad, Russia
}

\begin{abstract}
Rural areas require special treatment due to their natural and socio-economic vulnerability. Tourism activities meeting the principles and goals of sustainable development can serve as the main tool to ensure a synergistic effect for the development of rural areas. The study was carried out in the coastal area adjacent to the Curonian Lagoon of the Kaliningrad region of the Russian Federation as a promising area for rural tourism. The problems and prospects of sustainable development of these areas are assessed.
\end{abstract}

\section{Introduction}

The tourism industry, on the one hand, suffered most during the pandemic, being completely stopped in all sectors. On the other hand, regional actors (represented by both state and private companies and even individuals) are pinning their hopes on this very industry. In many respects, this resembles the period of perestroika, when economic experts noted the special role of tourism in the revival and restoration of regional economies. Unlike the 1990s, tourism itself has already undergone significant changes: from mass, traditional, to its sustainable forms. But, if in the 2000s, environmental focus in tourism was largely imposed by universal greening, then during the pandemic and in the postcoronavirus period, recreation outside the cities gained universal popularity, became a real "call of the time". At the same time, the tourism industry was ready for such a demand from potential consumers. After all, this demand largely meets the principles of sustainable tourism development. Former Secretary General of the World Tourism Organization Taleb Rifai said tourism is not just included in three of 17 universal goals: Goal 8 - decent work and economic growth; Goal 12 - responsible consumption and production; and Goal 14 life below water. But its pervasive characteristics make it an effective tool for achieving all 17 goals. For example, tourism can promote gender equality (Goal 5), contribute to the creation of sustainable cities and communities (Goal 11) and do away with poverty (Goal 1). Accordingly, by realizing these goals, tourism is able to contribute to the achievement of the overarching goal of the SDGs and the United Nations: promoting social progress, peace, and human rights [1]. In our opinion, this list can be more expanded because tourism contributes to almost every one of the 17 goals. For example, Goal 3 - Good health and well-being - is ensured by the very goal of tourism and recreation activities - recovery, new emotions, relaxation. Goal 9 - industry, innovation and infrastructure - has become doubly

${ }^{*}$ Corresponding author: kropinova2@mail.ru 
relevant in the coronavirus era: innovations are being introduced everywhere, from airports and aircraft provided with innovative ventilation, control systems, etc., to innovative individual beach cabins with bathtubs equipped with seawater systems. Goal 15 - life on land, can be achieved, among other things, through sustainable use of natural resources within specially protected natural areas, namely, subject to the development of ecotourism.

It is no coincidence that in 2020 UNWTO celebrates the Year of Tourism and Rural Development. Opening it, UNWTO Secretary-General Zurab Pololikashvili expressed the hope that the sector will lead to positive change in rural communities, creating jobs and opportunities, promoting economic growth, and preserving culture. [2]

\section{Materials and Methods}

\subsection{Methods used}

Speaking about the development of rural areas in the Russian Federation, we should, primarily, understand that this direction coincides with the state policy of the Russian Federation. In 2015, the 2030 Strategy for Sustainable Development of Rural Areas of the Russian Federation was approved.

Sustainable development of rural areas is understood as their stable socio-economic development, an increase in agricultural production, an increase in the efficiency of agriculture, the achievement of full employment of the rural population and an increase in its standard of living and rational use of land [3]. Among non-agricultural activities, rural tourism holds a special place as an important direction for the development of nonagricultural economic activities, an important source of jobs and the formation of additional income for the rural population. Thus, we are actually talking about a cumulative effect. Accordingly, the key task is to identify and stimulate precisely such levers that can generate a synergistic effect in tourism in rural areas (ecological, rural, etc.).

In our work, we used a whole range of methods to identify these components within two municipalities of the Kaliningrad region. First, statistical data were analyzed to identify territories defined as "rural" and, at the same time, favorable for the development of tourism. Secondly, a sociological survey made it possible to assess the demand for rural and ecological tourism among the residents of the region. Thirdly, the approbation of the theoretical provisions set forth in the article was carried out by us in the course of field studies using the example of the near-water areas of the Slavsky and Polessky municipalities of the Kaliningrad region. They are the ones that best meet the characteristics of "low-urbanized territories". In addition, during the expedition, elements of an emerging cluster within the study area were identified, and cluster interaction was assessed. This approach allowed us to confirm our hypothesis: the development of tourism in low-urbanized territories is the optimal form of sustainable tourism development and meets the main goals of sustainable development of the territory.

\subsection{Russian and foreign approaches to the definition of types of tourism activities in low-urbanized areas.}

Classifications of tourism by type of tourist activity distinguish a number of similar types of tourism, which, at the same time, have essential differences: ecological tourism, rural tourism (agritourism), sports tourism, adventure tourism. The concept of sports tourism provides for active routes that meet the requirements of sports classifications (Unified AllRussian Sports Classification of Tourist Routes) and the Regulations for certain types of sports tourism (hiking, water, cycling, mountain, skiing, etc.). Adventure tourism most 
often presupposes an active route with a scenario basis, high attractiveness and some suspense for the tourist. Active rest (active tourism) is a form of tourist activity associated with active movement along the route for the purpose of recreation, physical, intellectual, and moral rest and development [4]. Agritourism is one of the sustainable forms of land use in rural areas. In the western part of the Baltic Sea Region, it is most often referred to as "agritourism" or "farm tourism", in the eastern part - "rural tourism". [5].

The term "rural tourism" originated in foreign literature. The most common is interpretation by J.W. Kloeze, according to which, rural tourism is a concept that includes all tourism activities that develop in a rural environment. Another definition is given by P. Nistureanu: "Rural tourism is a concept that includes tourism activities organized and managed by the local population, based on a close relationship with the environment: natural and anthropogenic" [6]. Another definition is given by D. Matei: "rural tourism is a set of activities and services local farmers and peasants offer to attract tourists to their area, as well as to get additional income from this type of activity" [7]. Ecological tourism will be understood to mean both of its interpretations: "tourism aimed at visiting rare and unique natural complexes, landscapes, and objects", and "any type of tourism focused on the preservation of the natural environment." The current regulatory framework does not contain this concept, which is the reason for the broad interpretation of this concept and the discrepancy in its understanding by entrepreneurs employed in this area, state and municipal authorities and among tourists themselves. Also, as already noted, natureoriented types of educational tourism (observation and in-depth acquaintance with rare natural landscapes, rare species of plants and animals) and gastronomic tourism (acquaintance with the authentic culinary traditions of this territory) can actively develop in rural areas.

All of these types of tourism are united by their localization in a weakly urbanized territory and an orientation towards natural resource potential. At the same time, in the specified number of concepts for the purposes of this study, we believe it is necessary to highlight rural and ecological tourism, as they are united by an important essential feature: the accommodation of tourists in settlements, which increases the localization of added value in the specified territory. In contrast, sports and adventure tourism involve overnight stays in the field and minimal interaction between the tourist and the territory, while oneday stay within the framework of educational, gastronomic or event tourism (rural holidays and festivals) has a less pronounced economic effect. At the same time, it seems advisable, possible, and feasible to combine these types of tourism with overnight stays in rural areas.

However, the combination types of this sector of the economy that have developed within a specific territory are more appealing when considering tourism in relation to territorial development. And in this case the resource potential and factors of the development of the relevant territory will play a significant role. This allows us to talk about tourism within urbanized areas (urban spaces, or cities and suburbs), and lowurbanized (rural) areas, including natural areas (mostly specially protected nature reserves (SPNR). Due to the growth of preferences in outdoor recreation, and especially in the light of restrictive measures (including not only by regulatory authorities, but by citizens themselves), urban spaces are becoming less in demand, and SPNR have restrictions on visiting and by type of activity. Therefore, the main flow of tourists rushes to the countryside. In our opinion, the place of rural tourism in the system of leisure, tourism, and recreation is best represented by C. Hall and S. Page (Fig. 1) [8]. 


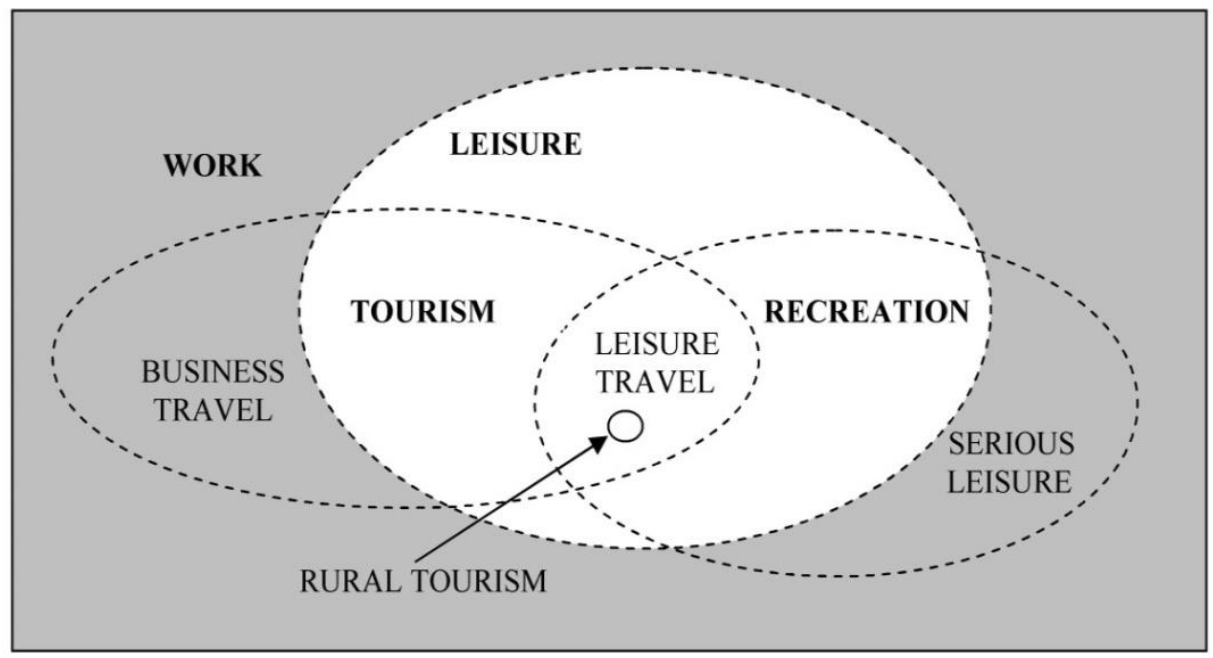

Fig. 1. Relationship between leisure, recreation and tourism (adopted from C. M. Hall and S. J. Page, 1999) [8]

In terms of the development of the territory, we should note the definition proposed by Nesterova: rural tourism (agritourism) is a sector of the tourism industry focused on the use of natural, cultural, historical and other resources of rural areas and its specifics for the creation, promotion, and implementation of an integrated tourist product [9].

\section{Results and Discussion}

\subsection{Rural areas of Slavsky and Polessky municipalities}

The analysis in paragraphs 2-3 allows us to define a low-urbanized (rural) area as one with a low population density. However, the main criterion will be a significant difference in the share of the urban population from the average values of this indicator for the region. Within the Kaliningrad region, such territories include municipalities located to the north and east of the regional center.

Our study will consider the development of rural and ecological tourism in the Polessky and Slavsky municipalities of the Kaliningrad region. These areas have similar geographic, landscape, and infrastructural features. As follows from Figure 2, in these territories, the rural population significantly predominates over the urban, and the centers of the administrative regions - the cities of Polessk and Slavsk - have a population of 6887 and 3984 people, respectively, which allows them to be classified as small towns. 

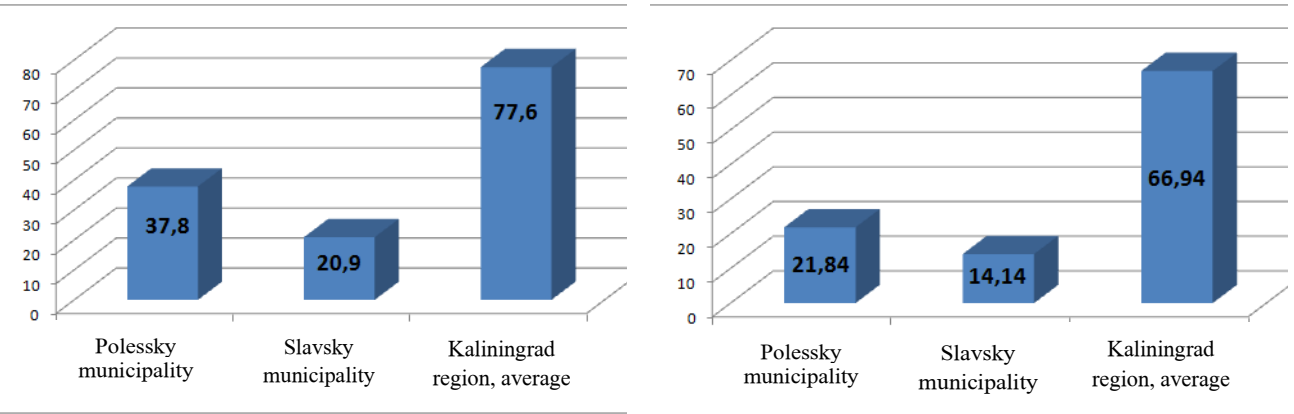

Fig. 2. Demographic characteristics of the Polessky and Slavsky municipalities of the Kaliningrad region: the share of the urban population (\%) and the population density per sq.km (complied by authors)

Some authors record the differences between the Russian model of urbanization and classical forms. Thus, by the end of the 1990s, large cities began to grow, and small towns began to decline. Since the beginning of the 2000s, the main centers have regained leadership in terms of growth rates, which does not fit into the classical patterns of staged development of urbanization processes. Moreover, the cities with the maximum population decline were the middle centers, some of which from the end of the list moved to the category of small cities, and the most dynamically growing centers from the top of the list of medium cities became large cities [10].

A group of regional experts have analyzed the sources characterizing the ecological and geographical features of the Kaliningrad region of the Russian Federation, which revealed a number of characteristic features of the regional ecosystem, namely geographic location, climate and weather, topographic and landscape forms, surface covers and soils, water, vegetation, environmental conditions [11]. In our case, the ecosystem approach serves as the basis for the implementation of ecological and rural tourism and allows us to ensure the basic sustainability of the development of low-urbanized territories/rural areas.

\subsection{Resource potential of Slavsky and Polessky regions}

Thus, the structure of the resource potential of rural and ecological tourism (Fig. 3) includes natural components (landscapes, unique objects of wildlife, climatic conditions, gifts of nature), and historical and cultural potential (historical buildings, monuments and memorials, hydrotechnical and other structures, cultural traditions).

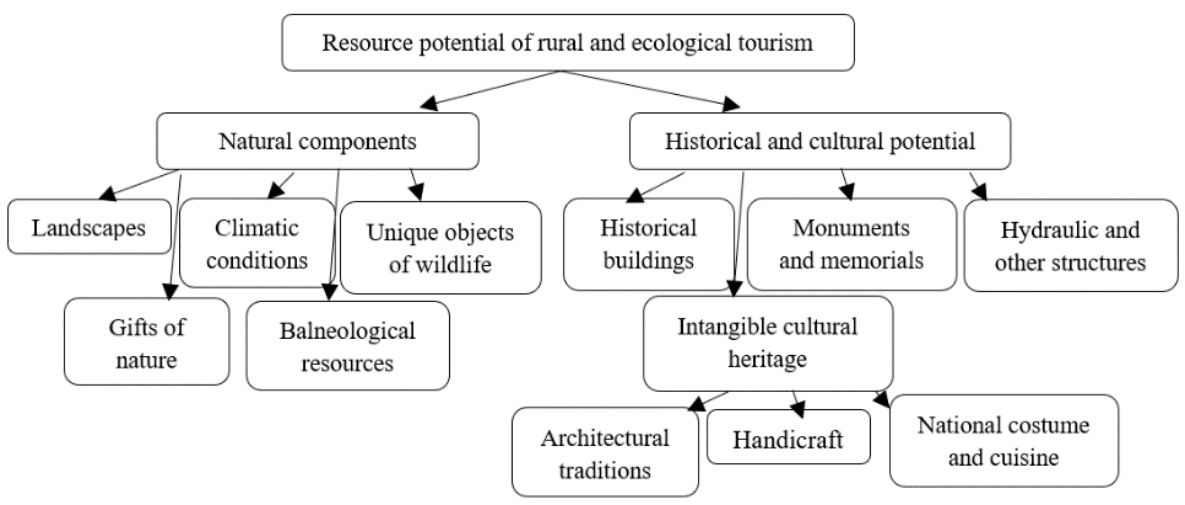

Fig. 3. Classification of resources for rural and ecological tourism (complied by authors) 
The interaction and progressive improvement of the triune structure of resources, their consumption infrastructure, and the tourism industry (service and promotion of services) serves as the basis for the development of any type of tourism. So, for example, underground mineral water is a resource, a pump room or a well is an element of infrastructure, the organization of health tourism using this resource is the activity of the tourism industry. Of course, the basis of this entire system is precisely the resources, and here we will consider the resources of rural and ecological tourism in more detail.

We can primarily divide the resources of these types of tourism into two large groups: natural resources and historical and cultural potential. At the same time, their ratio can be completely different: in one case, modern accommodation facilities can be used, but the main content of tourists' activities will be acquaintance with the unique nature of the territory, while in the other - the national and cultural flavor - historical estates, national dishes and traditions in the form of holidays and festivals will be the main content of the tourists' activity. Let us consider in more detail the category of natural components (for example, the Polessky and Slavsky municipalities of the Kaliningrad region).

The landscapes of these regions are quite original. In general, the average elevations of the surface of the region's territory range from 0 to $50 \mathrm{~m}$, the maximum is up to $248 \mathrm{~m}$. But the average level in the territories of these areas adjacent to the Curonian Lagoon from the east is $3 \mathrm{~m}$, the maximum heights are up to $12 \mathrm{~m}$, and some areas have a height below sea level - minus $2 \mathrm{~m}$. The territory is represented by swampy forests, swamps, lakes, wide river beds and canals without a pronounced flow. The territories are separated from the gulf by dams, the groundwater level is reduced due to targeted reclamation. The length of the waterways is 8.6 times longer than the length of unpaved and paved roads, as a result of which the area is called the "Kaliningrad Venice".

The local climate is Western European maritime. The sum of active temperatures is $2320^{\circ} \mathrm{C}$, the frost-free period is 181 days. The average temperature in July is $+17^{\circ} \mathrm{C}$, in January $-3^{\circ} \mathrm{C}$. The average annual temperature is $+8^{\circ} \mathrm{C}$. Annual precipitation averages about $800 \mathrm{~mm}$. The specified climatic conditions are favorable for most activities carried out in natural conditions.

Unique objects of wildlife are represented by nesting places of rare birds: black stork, gray heron, cranes, little bittern, hardhead, osprey, harrier, snake eagle, great spotted eagle, etc. Along with them, there is a large number of elk, beavers, wild boars and other mammals typical of areas with excessive moisture. The fish fauna is exceptionally rich, numbering 53 species of fish from 18 families. The area is rich in shellfish, as well as insects of interest both to professional entomologists and simply to amateurs. The vegetation cover is represented by forests (mainly - alder, birch, willow) and aquatic plants, including rare and aesthetically attractive ones - white water lily, yellow egg capsule, pseudoarion iris, reeds, cattail and others. The territory of the considered regions locates two protected areas - the Dyunny Zakaznik and the Gromovskiy Zakaznik, which are unique ecosystems of raised bogs and humid forests.

Gifts of nature. This term, which has no analogs in the English-language literature, means traditional technologies of ecological tourism: picking berries, mushrooms, medicinal herbs, honey production, fishing, collecting and eating mollusks, using natural materials for making crafts.

Cure resources. The town of Slavsk (formerly Heinrichswalde) has a spring and an associated mineral water swimming pool. The pool was built in 1935, a self-flowing well, 158 meters deep. The water of this spring, containing mineral salts, silver, and sulfur, was supplied to Dresden at the beginning of the XX century and was known far beyond the borders of East Prussia.

We have also detailed the historical and cultural potential of this area: the first group of resources - historical buildings - includes 15 churches, 2 castles belonging to the objects of 
historical and cultural heritage of regional and local significance. Kirches date back to 1400-1926, and most of them are in satisfactory condition. Individual buildings in settlements (residential buildings, schools, administrative buildings) are also architectural landmarks.

Monuments and memorials are represented by monuments and memorable signs of the Great Patriotic War and the First World War. Hydraulic engineering objects play a special role as resources of the historical and cultural heritage: the gateway on the river. A $12 \mathrm{~m}$ high sailor's boat, bridges, including those built by the unique Dutch technology by the settlers - Mennonites. The territory of the region locates water pumping stations and a network of drainage canals, which is a monument of the hydrotechnical culture of the XVII-XX centuries. Intangible cultural heritage, which we divided into 3 components, plays a special role in the development of tourism in these territories.

Architectural traditions. This region combines the architectural traditions of wooden and stone architecture, which were formed here by the fusion of the cultures of the Prussians, German settlers of the XVI-XVII centuries, Lithuanians, Mennonites and other peoples. Many buildings are being restored, rebuilt or built from scratch today with respect to these architectural traditions.

Folk crafts. The manufacture of traditional fishing vessels and the general traditions of navigation, smoking fish, weaving from straw and willow bark, brewing, making cheese are actively revitalized traditions being reflected today in the development of rural and ecological tourism.

National costume and cuisine. Sophisticated, close to event-like forms of organizing rural tourism (holidays, festivals) provide for the active use of these traditions, and it is the national cuisine that gives a national flavor when accommodating guests in rural estates.

The above components fit well into weekend routes [12]. The analysis performed allows us to assert that a tourist cluster is being formed within the considered rural area.

\subsection{Economic aspects of rural tourism development}

As noted above, the importance of the development of rural and ecological tourism is recognized at the federal level in Russia precisely in the context of the dynamic development of rural areas, the formation of additional added value, and the diversification of the economy of rural settlements [3]. However, the results of the study of the current state of rural tourism in Russia, conducted by ARSI with the support of the Presidential Grants Fund, show that only 13 out of 71 constituent entities of the Russian Federation that took part in the survey, had introduced the term "rural/agricultural tourism" into the regional legislation, and only 6 entities have an independent concept of rural tourism development. At the same time, the number of tourism consumers in rural areas is $22 \%$ of all domestic tourists, which generates about 30 billion rub. per year of income to local residents (over $300 \mathrm{mln}$. Euro) [13].

Our sociological research has shown that $50 \%$ of the respondents (residents of the Kaliningrad region) prefer a reclusive vacation with health improvement. Also, $56 \%$ have never rested in such accommodation facilities in the Kaliningrad region, 26\% have been once. It can be assumed that about $30 \%$ of the population remains uncovered by this type of recreation, which means that the lost benefit can be estimated at about 40 billion rub. per year. These calculations fit well into the assessment of the role of rural tourism in the development of rural areas. Thus, An \&Alarcón conducted their study that involve review of 76 articles published in high-ranking journals in 2009-2019 dedicated to the sustainable development of rural tourism. The articles were distributed by keywords as follows: "sustainability of livelihood" - 53 articles, "quality of life" - 58 articles [14]. Hence, most researchers have concluded that rural tourism can be a driver of economic income and 
employment that contribute to livelihoods. At the same time, 60 conclusions indicate that the development of rural tourism has both positive and negative effects on the social life of the community and changes the rural environment [14].

Hence, the question arises: if the market for this type of activity reaches its saturation peak, will the territory remain "rural"? Will it retain its attractiveness to visitors? Will there be a synergistic effect consistent with the principles of sustainable development? There is no doubt that from the perspective of Goal 1 - to end poverty, Goal 8 - decent work and economic growth; Goal 12 - responsible consumption and production - is undeniable. But Goal 15 aiming at conservation of terrestrial ecosystems (protecting and restoring terrestrial ecosystems and promoting their sustainable use will help achieve sustainable development) may be under threat.

Can the desire to achieve some SDGs be compensated by the "failure" of the other goal(s)? This issue requires more detailed study. It is no coincidence that a whole issue of one of the leading Russian scientific and practical journal - "Services and tourism: current challenges", which was named “"TOURISTS - GO HOME!":Factors and problems of over tourism», is devoted to this problem $[15,16]$. It is worth agreeing with S. Iakovleva that the very fact of the appearance of the term "over tourism" is a recognition of the inconsistency of the concept of sustainable tourism in specific centers and localities [17]. A number of authors suggest using the factor of tourist satisfaction as an indicator of the saturation of the territory (for example, accommodation facilities in the coastal zone) [18]. (tourist satisfaction is a perception factor that can be used to estimate when a coastal tourism area may be considered saturated by tourist accommodations upon reaching a minimum level). Campón-Cerro, Hernández-Mogollón, and Alves, H. [19] state that loyalty directly affects the economic aspects of sustainable development and indirectly affects the social and environmental aspects.

Thus, a violation of the principles of sustainable development, in addition to the degradation of natural complexes, leads to another negative consequence - a decrease in the attractiveness of the territory for tourists, and therefore in the socio-economic effect of tourism. That is, the synergistic effect will start working backwards.

\section{Conclusion}

Thus, we can conclude that the main problems that we have identified in the development of rural and ecological tourism in rural areas are:

-insufficient infrastructure development (transport, mobile communications, insufficient gas supply as a cheap and environmentally friendly source of energy);

- low investment attractiveness and insufficient financial resources;

- insufficient level of professional education in economics and tourism among the majority of the population of these territories;

- in general, low-intensive development due to insufficient planning and the lack of a coherent tourism strategy.

At the same time, the study revealed the following aspects of the importance of rural tourism development in the context of the concept of sustainable development:

- the development of rural and ecological tourism is one of the most promising areas for the development of low-urbanized regions and municipalities. This type of tourism plays an important role in conditions of poor financial security of the territories, which is most often characteristic of rural settlements. A high degree of development of rural tourism can become the basis for the progressive socio-economic development of rural areas and the state in general;

- the basic mechanisms of influence of the development of rural and ecological tourism on improving the quality of life in municipalities are: increasing the revenue base of local 
budgets, creating new, highly qualified jobs and diversifying the labor market, supporting the least socially protected segments of the population, expanding and diversifying the sale of agricultural products and items folk craft; improving the image of rural areas, increasing their investment potential;

- in terms of a tourist, rural tourism allows achieving a health-improving effect due to recreation in ecologically clean areas; join a healthy lifestyle, get acquainted with local attractions, traditions and culture, reduce financial and time costs by localizing recreation in a certain region;

- in terms of the state, the development of rural tourism increases the share of inbound and domestic tourism, increases tax revenues, improves the quality of life of the population, reduces the imbalance of incomes between the city and rural areas, reducing social tension and outflow of the population from rural areas; preservation of cultural and historical traditions; development of social entrepreneurship in the countryside.

In our opinion, the initiatives from the Russian government are, first, the All-Russian competition for the creation of tourist and recreational clusters (TRC) and the development of ecotourism in Russia, held in August 2020; secondly, a competition for grant support of projects for the development of domestic and inbound tourism will contribute to the development of tourism in rural areas. After all, the first one was organized specifically for new infrastructure facilities, supposed to be located within specially protected natural areas. The second one involves the development of new tourist routes, including within specially protected nature areas.

\section{References}

1. Official webpage of UNWTO. UNWTO annual report 2016,https://www.unwto.org/

2. International tourism growth continues to outpace the global economy (2020), https://www.unwto.org/

3. «On approving the Strategy of sustainable development of rural areas of RF up to 2030» of 02.022015 The Decision of the RF Government №151-p.

4. A.N. Kugusheva, Proceedings of the Russian scientific and practice conference FGBOU VPO "RGUTiS": Institute services, 80 (2011)

5. E. Kropinova, Rural Development and Land, 130 (2012)

6. Europe in figures. Eurostat Yearbook 2010, http://epp. Eurostat.ec.europa.eu

7. European Commission, Marketing Quality Rural Tourism Leader Technical Dossier (1995)

8. C.M. Hall,S.J. Page, The geography of tourism and recreation: environment, place, and space, 4 (1999)

9. N.A. Nesterova, Recommendations on organization rural guest houses(2011)

10. T.G. Nefedova, A.I. Treivish, Regional Research of Russia, 9, 1 (2019)

11. L.L. Emelyanova, E.G. Kropinova, K.J. Voloshenko, The Agricultural Resources, Governance and Ecology, 11, 158 (2015)

12. A.Yu. Anokhin, E.G. Kropinova, Service and Tourism: Current Challenges, 14, 50 (2020)

13. I.V. Lebedeva, S.L. Kopylova, Results of the research "Recent state of rural tourism in Russia. Finding problems and prospects of rural tourism development in Russia(2019)

14. W. An, S. Alarcón, Sustainability, 12(18), 7758 (2020)

15. O.E. Afanasiev, Service and Tourism: Current Challenges,13, 5 (2019) 
16. A.Yu. Sanin, T.O. Paranina, Service and Tourism: Current Challenges,4(2019)

17. S.I. Yakovleva, Service and Tourism: Current Challenges, 4(2019)

18. M.S. Cruz, M.P. Zaragoza, Analysis of the Accommodation Density in Coastal Tourism Areas of Insular Destinations from the Perspective of Overtourism(2019)

19. A.M. Campón-Cerro, J.M. Hernández-Mogollón, H. Alves, Journal of Destination Marketing \& Management(2017) 